\title{
Prospects for the use of peat in metallurgy
}

\author{
T B Ykonovskaya ${ }^{1,2}$ and A I Zhigulskaya ${ }^{1}$ \\ ${ }^{1}$ Tver State Technical University, 22, pr. Afanasiy Nikitin embankment, Tver, \\ 170026, Russia \\ E-mail: 'tby81@yandex.ru
}

\begin{abstract}
A large number of metallurgical industry enterprises in the regions of Russia mainly use imported and rather expensive coking coal or natural gas for steelmaking. However, almost all regions of Russia have large reserves of peat, which can replace expensive hydrocarbon raw materials in metallurgical processes. For this reason, the use of peat raw materials (briquette, piece) in metallurgy is of scientific and practical interest. The properties of peat briquettes and pellets in the process of pyrometallurgical processing are set by the methods and technological parameters of their preparation. The article presents the results of a study of the influence of the type and quality properties of peat on the technological process of recovering peat compositions prepared on the basis of iron ore from the Bakchinsky deposit. Peat of the Vasyugan peat massif was used for the production of peat melting compositions. Experimental data showed that, for peat compositions, low-ash peat on the watershed is suitable. The use of peat melting compositions allows us to solve the problem of the return of ore dust and substandard ore in the smelting processes and thereby develop a rational low-waste technology.
\end{abstract}

\section{Introduction}

Ensuring the growth of metallurgical production in Russia is associated with the problem of meeting the demand for coking coal. Despite the increased pace of coal mining in Russia, its cost is increasing annually. It should be noted that coal is an exhaustible natural resource, and therefore, the reserves of high-quality coking coal in Russia are depleted. Coking coal reserves are estimated at 42.3 billion tons, of which more than $70 \%$ are accounted for by the Kuznetsk coal basin, while the estimated resources are about 390 billion tons.

The coking coal market structure is an oligopoly with elements of a local monopoly in its individual segments and for certain brands of coal. In addition, there is a rather strong 'coal lobby' thanks to which Russian coal mining companies receive financial support from the state in the form of tax and tariff benefits, as well as direct subsidies and soft loans for development and production modernization. Specialists of the Mining Research Institute named after A A Skochinsky determined the dependence of the price of coal on the price of oil products [1,2], however, despite the drop in exchange prices for oil observed in March-April 2020, the prices of coking coal are stable and show a slight increase. Although prices on the global coal market are falling amid the economic crisis.

Demand for coking coal in the future will continue and even grow, due to the increasing complexity of mining and geological conditions for their development and the quality of coal raw materials. The main value of coking coal in producing coke for metallurgical processes in the blast furnace production of steel and other metals. The annual demand of the largest metallurgical plants in Russia for coking coal is 20.8 million tons. However, the development of new deposits requires significant investment. In addition, in the raw material component of the cost of pig iron, $40-50 \%$ is 
accounted for by coke. In this regard, the search for an alternative to coking coal raw materials for the production of coke, which will replace expensive coal and improve the quality of steel products, becomes a very urgent task. In this regard, peat has several advantages. With a high yield of chemical products of pyrolysis, a blast furnace process on peat can produce high-quality cast iron, such as, for example, coal, which is used for smelting high-quality steel.

The qualitative properties of coal for the purposes of metallurgical processes are characterized by the level of sintering and the presence of impurities of such substances as phosphorus and sulfur. Therefore, metallurgical enterprises have certain requirements for the quality of coal coke used, among which the most important is the ash indicator. As you know, the higher the ash content, the worse the quality of coal coke for the blast furnace process. In this regard, for metallurgical processes, the ash content of the charge should be no more than $10 \%$, the yield of volatile substances up to $30 \%$, and the sulfur content not more than $1 \%$.Since natural fuel is used for the production of coke, peat can be used for these purposes. Unlike hard coal, peat has a low phosphorus and sulfur content, is a common and renewable resource, with up to $90 \%$ of peat reserves concentrated in the North-West Federal District and Western Siberia, in the metallurgical regions of Russia. Peat is an organic fuel and a valuable chemical raw material for a wide range of industrial uses. Many geologists [3-5] hypothesize that peat is the initial stage of coal formation. For different types of peat and the types of their formation, the ash content varies widely; for high peat, the ash content is from 0.5 to $5 \%$, for transitional peat from 6 to $10 \%$, and for low-lying peat more than $10 \%$. Therefore, for the production of peat coke in terms of ash content, higher peat of a watershed type of formation is more suitable. And from a technical and economic point of view, in order to reduce transport costs, stocks of low-ash peat should be very close to metallurgical production (up to $100 \mathrm{~km}$.). This issue is especially relevant for the Tomsk region in whose territory the Vasyugan-Tymsky complex of a wide range of natural resources of peat, iron ore, oil and gas are located. Peat coke is suitable when used as a thinning element of the mixture, as well as for the agglomeration of iron ores. Peat coke, lump peat and milled peat can serve as blast furnace fuel for foundry purposes. Due to its high reactivity, peat is a good reducing agent for iron. This corresponds to one of the main directions of progress in ferrous metallurgy - the intensification of the blast furnace process through the improvement of the aerodynamic properties of charge materials by creating a 'charge' based on a powder of finely ground concentrate - an iron ore enrichment product. In addition, quite a lot of substandard, 'waste' rock accumulated in the territory of iron ore mining enterprises, which is characterized by a low content of iron ore and forms artificial technogenic deposits. This 'waste' breed can also be used as raw material for the 'charge' and the extraction of steel [6-8].

Along with coke, peat semi-coke is successfully used in metallurgical processes, as well as for the cementation of carbon steels, the manufacture of sorbents in a glass charge. In Germany, peat coke and semi-coke were used for smelting ferroalloys, for heat treatment in mechanical engineering, for the production of refractory bricks, and for the production of activated carbon and carbon disulfide. However, it should be noted that in foreign countries the use of peat in metallurgy is not widespread. The scientific interest in the use of peat is also extremely weak.

\section{Materials and methods}

For several years, scientists from Tver State Technical University conducted research on peat and ore materials obtained back in 1980 from the Vasyugan peat deposit and the Bakchinsky iron ore deposit, located in the Tomsk Region and bordering each other. In a problematic laboratory, the influence of the initial moisture content of peat, the type of peat, the intensity of its processing, the molding pressure, the degree of grinding of ore and fluxes and their amount, the coking regime and other factors on the strength of peat briquettes and pellets was studied.

The technique for producing peat briquettes and pellets is based on the theory of structure-forming processes in peat colloidal systems according to the principles of physicochemical mechanics of dispersed materials. This theory was developed by the founding scientists of the Peat School of Tver State Technical University: Afanasyev A F, Gamayunov N I, Volarovich M P, Churaev N V, 
Lykov A V Research on this issue is ongoing [8-10]. According to a number of its properties, peat is a model of capillary-porous bodies, and these properties have a significant impact on the formation of the strength structure of peat briquettes and pellets. Peat is a dispersed multiphase system. The presence in it of hydrophilic and hydrophobic organomineral colloids, solutions and dispersions of low and high molecular weight compounds leads to the formation of various solid phase associates. The higher the density and strength of peat briquettes and pellets, the better the process of iron recovery. Granules were made from milled peat that passed through the crusher and former. The granules, dried to $40 \%$ humidity, were loaded into a coking shaft. Peat coke, similar in technological characteristics to charcoal, but possessing the strength of coal coke, practically does not introduce undesirable impurities into cast iron. At the same time, from 6 tons of peat, 1 ton of coke can be obtained. The object of study of this work is peat material restored at a temperature of $500-1100^{\circ} \mathrm{C}$. Peat obtained in 1980 from site No. 3 of the Vasyugan deposit (Figure 1) was used to recover iron from ore. The samples relate to high peat, accounting for $24 \%$ of the total reserves of plot No. 3 , and prevailing lowlying peat in the plot (52\% of the reserves). Peat data are considered as raw materials for the production of peat materials (TPM). TPM consists of $70 \%$ ore and $30 \%$ admixtures of peat of the high and low types. The ore is a loose mass of brown color, consisting of goethite and hydrogetite [11-14].

Table 1. Peat characteristics of plot № 3 of Vasyugan field.

\begin{tabular}{ccccc}
\hline $\begin{array}{c}\text { Sample } \\
\text { number }\end{array}$ & Peattype & Type of peat & $\begin{array}{c}\text { Degree of decomposition, R } \\
\%\end{array}$ & $\begin{array}{c}\text { Ash content, } A^{\mathrm{c}} \\
\%\end{array}$ \\
\hline 1 & Lowland & $\begin{array}{c}\text { Sedge- } \\
\text { sphagnum }\end{array}$ & 35 & 5.5 \\
2 & Upstream & Fuskum & 35 & 1.4 \\
\hline
\end{tabular}

Ore chips were laid out on a peat mass in an even layer of $1-2 \mathrm{~cm}$. The resulting peat mass was passed through the screw twice and formed from it cylindrical samples with a diameter of 34-35 mm by extrusion in a special matrix. TPM samples were dried in a laboratory room to a constant weight, periodically measuring the size and mass of the moldings to calculate the shrinkage coefficient. The obtained TPMs were tested for their metallization upon heating at a constant rate of $5{ }^{\circ} \mathrm{C} / \mathrm{min}$. Samples were placed in a $300 \mathrm{ml}$ heat-resistant steel retort and heated in a TEP-1 crucible electric furnace to temperatures of $500-1000{ }^{\circ} \mathrm{C}$ with an interval of $100{ }^{\circ} \mathrm{C}$. Combined gas and decomposition products of TPM were discharged through a fitting in the lid of the retort into condensation equipment. Upon reaching the final heating temperature, the retort was removed from the furnace and cooled to room temperature. Given the pyrophoricity of the reduction products upon cooling in the retort, an excess nitrogen pressure was maintained for half a day. To heat TPM to a temperature of $1100{ }^{\circ} \mathrm{C}$, a hightemperature tube furnace was used. The composition of iron ore of total iron contained about $38 \%$, silicon oxide $-24 \%$, calcium oxide $-0.64 \%$, aluminum oxide $-5 \%$, phosphorus pentoxide $-1.17 \%$.

\section{Discussion}

The resulting cast iron contained silicon $-1.1 \%$, vanadium $-0.06 \%$, phosphorus $-0.5 \%$, manganese $021 \%$. The slag contains: silicon oxide $-43.82 \%$, calcium oxide $-30.36 \%$, aluminum oxide $-15 \%$, iron oxide $-3 \%$, phosphorus pentoxide $-0.1 \%$ magnesium oxide $-2 \%$. The close contact of the reducing agent and the peat ores, as well as the high volatility of peat, favorably affect the recovery of iron ore. It is shown that the rate of reduction of magnetite and brown iron ore in the presence of peat is higher than with other solid reducing agents. This circumstance can significantly reduce the process time and lower its temperature. All this opens up favorable prospects for the use of peat materials by the method of a problematic laboratory for direct (non-explosive) iron production or other metallurgical processes where a highly reactive reducing agent is required. 


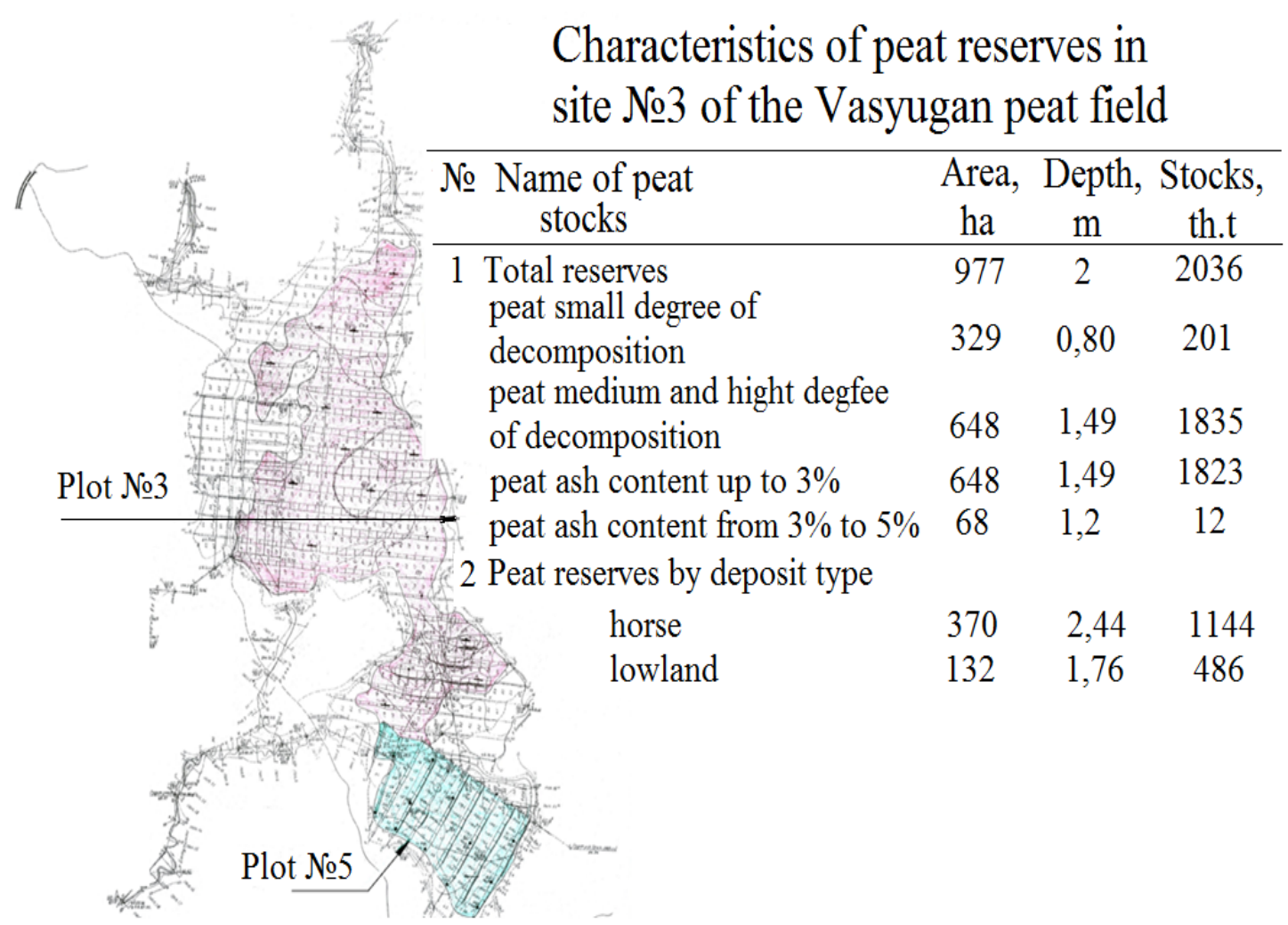

Figure 1. Map-scheme of the southern part of the Vasyugan peat massif (plots № 3 and № 5).

The complex chemical and metallurgical (blast furnace) process is based on the use of dry lump peat or 'mono-mixture' that has not undergone preliminary coking or thermal briquettes as blast furnace fuel. In this case, the blast furnace combines the process of smelting cast iron with the process of coking peat and, along with cast iron, produces high-calorie gas and other chemical products of peat pyrolysis: peat resin, gas gasoline.

A wide range of hydrocarbons and organic oxygen compounds can be obtained on the basis of carbon monoxide, which is the predominant component of blast furnace gas and water vapor, when these components are passed through the catalyst at a temperature of $220-280{ }^{\circ} \mathrm{C}$. Gas can be used economically to generate electricity or for the synthesis of ammonia.

\section{Conclusion}

As a result, the degree of reduction of iron from TPM was $92 \%$, the degree of metallization after firing was $94 \%$. Experimental melting of porous iron gave a metal with a carbon content of $0.05 \%$, sulfur and phosphorus less than $0.05 \%$. In addition, more durable and dense TPMs are obtained when using peat. High thermal strength of briquettes and pellets from TPM is associated with the emergence of a metal frame in this case, with an increase in the degree of recovery, the thickness of the metal frame increases.

Peat for smelting cast iron can be either upland or lowland, provided that the ash content should not exceed $10 \%$ and the humidity not more than $30 \%$. The resulting pressed peat piece from which coke is produced must have a mechanical strength of at least $2 \mathrm{MPa}$ with a low content of fines and sulfur. As a disadvantage of peat coke in comparison with coal coke, there is not much mechanical strength. However, TPMs with various types of peat had good physical and mechanical characteristics both in cold and in heated states. Also, instead of iron ore, you can use its dust and get briquettes and pellets of TPM with the organization of milk waste technologies. 


\section{Results}

In conclusion, we can say that the use of peat in metallurgy shows good prospects for this area. Shaping waste from metallurgical processes with peat makes it possible to obtain TPM briquettes and pellets with desired quality properties in ash, moisture, sulfur and phosphorus, and mechanical strength. The problem can arise only in the absence of a peat deposits base with specified geological characteristics of peat raw materials for the production of peat coke.

\section{References}

[1] Mikhailov A, Zhigulskaya A and Yakonovskaya T 2017 Strip mining of peat deposit mine / Planning and equipment selection: mpes 2017. Proceeding of the 26th International Symposium (Luleå, Sweden)

[2] Mikhailov A V, Zhigulskaya A I and Yakonovskaya T B 2017 Excavating and loading equipment for peat mining IOP Conference Series: Earth and Environmental Science

[3] Zhigulskaya A I et al 2016 Processing wood resources of peat deposits to produce environmentally friendly products Actual problems of life safety and ecology: Sat. scientific tr II international scientific-practical conference with a scientific school for youth (Tver: TSTU)

4] Zyuzin B F et al 2016 Complex use of peat and wood resources Problems of the rational use of natural resources and sustainable development of Polesye: Sat. doc International scientific conference: in $2 \mathrm{vol}$

[5] Yakonovskaya T B et al 2016 Rational use of peat resources in bioenergy of the Tver region. Socio-economic and environmental problems of mining, construction and energy ed. R.A. Kovaleva

[6] Gebler I V, Smolyaninov S I and Neznanov A G 1963 The influence of the degree of grinding of ore and fluxes on the quality of peat-based fuel-melting materials Bulletin of the Tomsk Polytechnic University. Geo-Resource Engineering vol 112

[7] Smolyaninov S I and Denisov A M 1963 The effect of briquetting temperature and pressure on the mechanical properties of peat briquettes Bulletin of the Tomsk Polytechnic University. Geo-Resource Engineering vol 118

[8] Smolyaninov S I 1974 Development of the fundamentals of the method of chemical and metallurgical use of peat Bulletin of the Tomsk Polytechnic University. Geo-Resource Engineering vol 118

[9] Smolyaninov S I and Krinitsyn G G 1965 Fuel-melting materials from peat of low humidity Bulletin of the Tomsk Polytechnic University. Geo-Resource Engineering vol 126

[10] Grevtsev N V, Aleksandrov B M and Plekhanov K A 2003 Prospects for the use of peat carboncontaining and ore-containing briquettes in metallurgical processes Bulletin of the Ural State Mining and Geological Academy vol $\mathbf{1 7}$

[11] Patel N, Cameron I and Gordon Y 2016 Strategies for implementing direct reduction technologies in an integrated steel plant Iron and steel technology vol 13 no $\mathbf{4}$ pp 75-81

[12] Steinacker S and Antrekowitsch J. 2017 Hydro metallurgical treatment of a copper-ironmolybdenum alloy World of metallurgy - erzmetall vol 70 no 6 pp 319-26

[13] Ravisankar V, Venugopal R and Bhat H 2019 Investigation on beneficiation of goethite-rich iron ores using reduction roasting followed by magnetic separation Mineral processing and extractive metallurgy: transactions of the institute of mining and metallurgy vol 128 no 3

[14] Huang Y, Zhang L, Wang M and Aindow M 2019 Fabrication of a multi-phase porous hightemperature Mo-Si-B alloy by in situ reaction synthesis Powder metallurgy vol 62 no 4 